\title{
SWOT Analysis of Central Economical Zone Developing E-Commerce-Take Henan for Example
}

\section{Fengna Ge}

Research Institute of Management Science and Engineering, Henan University, Kaifeng, China

Email: gena2002@163.com

Received 14 May 2016; accepted 19 June 2016; published 22 June 2016

Copyright (C) 2016 by author and Scientific Research Publishing Inc.

This work is licensed under the Creative Commons Attribution International License (CC BY). http://creativecommons.org/licenses/by/4.0/

(c) (i) Open Access

\begin{abstract}
Central economical zone is an important part of China's regional economy. As a new growth pole, it will have a programmatic guidance to the reconstruction of the regional economy territory. Its development will have a significant positive impact on our country. To grasp opportunities and develop, we must start from the reality of the province and develop e-commerce, making it become the new economic growth point. This article utilizes the SWOT analysis and combines internal and external environment of electronic commerce, pointing out opportunities and threats that Henan face when developing electronic commerce.
\end{abstract}

\section{Keywords}

Central Economical Zone, Henan Province, E-Commerce, SWOT Analysis

\section{Introduction}

SWOT analysis evaluates enterprises comprehensively combining internal and external environment and makes strategy plan using matrix. The analysis of strengths and threats focuses on enterprises' strength and the comparison of the competitors. While the analysis of opportunity and threat focuses on the changes of external environment and the effect on the enterprise. The same change of the external environment brings different threat and opportunity to enterprises having different resources and strengths. Therefore, they must be put together to reflect the cross effect of matrix. SWOT analysis helps to convert threats and meet the challenge in the process of developing e-commerce, take the advantage and seize the opportunities, and thus speeds up the development of electronic commerce in central economical zone. 


\section{Strengths}

\subsection{Henan Is the National Comprehensive Transport Hub and Logistics Center}

Henan province is located in the central of China connecting the east and the west, and has a convenient transportation. Beijing-Guangzhou and Longhai railway intersect in Zhengzhou, highlighting the center of traffic, logistics and business. Zhengzhou becomes the modern logistics service center to serve the central and west, face the whole country and link the world. National cable "three vertical and three horizontal" transit makes Henan have the advantageous conditions to develop electronic commerce.

\subsection{Henan Has Broad Market. Agricultural Market Has Tremendous Potential}

Henan is a big agricultural province. Agricultural products such as grain, oil, vegetables, tea, tobacco and cotton occupy an important position in the country. Although agricultural products are rich in our province, markets scatter. However, the application of e-commerce in agricultural market can put the scattered market together through the Internet, improve market competitiveness of agricultural products in our province, and create a brand.

Tourism will bring new energy. Henan has rich tourism resources. Experience tour of ancient capital group taking Zhengzhou, Luoyang, Kaifeng and Anyang as the main body, Chinese Kung Fu tour taking Shaolin and Taiji as representatives, leisure tour taking Funiu mountain as the center, South Taihang mountain and Dabie mountain as wings convert from traditional tour to modern leisure tour. Tourism industry needs the cooperation of transportation, commercial and other departments. E-commerce can relate scenic spots, travel agencies, hotels, inns and other related industries together, attracting more tourists with the aid of internet. According to that, tourism electronic commerce is a new opportunity to develop e-commerce [1]-[10].

The logistics industry development space is enormous. Construct a modern logistics system taking Zhengzhou as the center, regional central cities as node, Logistics Park as the carrier, the third party logistics enterprise as the supporter. Promote the construction of international logistics center, optimize the layout of logistics functional areas, perfect public facilities of multimodal transport, form a logistics hub serving the central, facing the whole country and connecting the world. Strengthen the regional logistics hub construction of Luoyang, Anyang, Shangqiu, Xinyang, Nanyang, etc. Vigorously develop food cold chain, medicine, steel, automobiles, home appliances, textile, garments, postal services, food, flowers, building materials and other professional logistics, promoting the linkage development of logistics industry and manufacturing. Speed up the construction of regional distribution centers and distribution network. Vigorously introduce and cultivate the third party logistics enterprises. Therefore, the prospect of logistics electronic commerce in Henan is considerable.

\subsection{Relatively Strong Industrial Base}

Industries like aluminium industry, food industry, petroleum chemical industry, chemical, machinery, automobile parts, textile and others develop fast in Henan. At present the whole scale of aluminum is in the first place. Food processing industry is in the top place in the country. Coal chemical, petroleum chemical industry, automobile, automobile parts, equipment manufacturing industries also present a welcome development momentum, having a certain amount of competitive advantage. The trend of industry elements cluster reveals. Zhengzhou high technology industry base was constructed, taking electronic information, biological medicine and new materials as representatives. Luoyang hi-tech industry base was constructed, taking electronic information material and advanced manufacturing industry as representatives. Anyang, Nanyang, Hebi electronic components industry was also established.

\subsection{Government Build Good Development Environment}

Strengthen the infrastructure construction of regional spatial information. Establish and perfect the information and resources sharing system. Deepen the information and technology application. Implement important engineering projects like digital Henan, wisdom of the central, wireless city, central data base and internet city. Improve the position of Zhengzhou as information distribution center and communication network exchange hub. Promote the development of information communication technology industry like mobile communications, the next generation of the Internet and the internet of things. According to the country's whole deployment, com- 
prehensively promote the "three nets fusion" of telecom network, broadcasting television network and Internet. Speed up the construction of optical fiber accessing network and popularized extensions. Construct broadband central plains. Implement the project of upgrades of the mobile communication network. Expand the coverage of the third-generation mobile communication network. Optimize the layout of new-generation mobile communication. Speed up the development of the internet of things. Implement key field demonstration projects of the internet of things. Support major application network platform and the infrastructure construction of information security. Improve the emergency system of disaster tolerance and information safety. Enhance rural agriculture informatization service level.

\section{Weaknesses}

\subsection{Shortage of Funds, Little Input for Information Industry}

From the development of information industry of developed and merging industrial countries, their input for it is great. Information industry investment in developed countries like the United States accounted for about 3\% of GDP. In domestic cities like Guangdong, Jiangsu, Shanghai and other developed provinces and cities, it has accounted for $115 \%$, and there is a rising trend. But the investment in Henan is very few. Besides, Henan is located inland. Economic development is relatively backward. The overall development environment is worse than coastal open cities. The narrow financing channel and the shortage of capital restrict the development of information industry. The situation that the industry level also is relatively backward in western remote areas has certain conditionality for the development of e-commerce. In the industrial structure, the proportions of agriculture and the traditional industries are great and information service industry occupies a little of the third industry. In the industrial development level, the modernization of agriculture is low. Many traditional industries belong to the sunset industry. The production technology falls behind, the adaptability to the market is weak and economic efficiency is not high. Most of the third industries are labour intensive industry, whose technical content is low. Information technology industry doesn't have advantages in western remote areas, lack of information product development industry having size effect. Therefore, the degree of influence which informatization has on production and management is far less than eastern regions.

\subsection{The Restriction by Traditional Ideas, Low E-Commerce Consciousness}

The influence which electronic commerce established in the modern information technology has on people will be comprehensive. It has great differences with old life traditions and old habits. So, electronic business transforms traditional habits and concepts. Whether people can receive new customs and ideas is influenced by many factors, including economic factors and non-economic factors, such as social environmental open degree, difference degree of new things and old habits, the cost people pay to receive new things, the age structure, character, interest of the main body. Influence by geographical environment, social environment is relatively close and open degree is relatively low in western remote cities. As traditional culture and habits are strong, the internal and external force for people to change the traditions is relatively weak. The low economic level brings about the high cost of implementing electronic commerce. Therefore, the traditional ideas and habits objectively have greater role of hysteresis for the development of the electronic commerce. Our province's economy is relatively backward. People's thought is relatively close, lack of clear understanding of the importance and the necessity of the development of electronic commerce. Mainly displays in: part of the city governments don't recognize the important role they plays in electronic commerce development and they don't take positive powerful policy to promote the development of the electronic commerce. Part of the enterprises have weak consciousness to develop electronic commerce, focusing too much on short-term profits, so that the management level is backward and enterprise's development lack staying power. The enthusiasm people have on participating in electronic commerce is insufficient. The traditional shopping habits are still hard to change, so as to restrict the fast development of online shopping.

\subsection{Structure of Talents Is Not Reasonable}

Industrial structure of Henan province is based on labor-intensive and primary processing products. The features of extensive economic growth are distinct. In recent years, limited resources are concentrated on industries like coal, electric power, building materials and nonferrous metals, which highly dependent on natural resources and 
ecological environment and can't give full play to human resources and knowledge resources, which make the opportunity cost of developing information industry greatly increase. The phenomenon of high quality talents erosion is more serious. At the end of last year, the total amount of technology personnel are only $5313 \%$ of Shandong, and invention patent is only $39 \%$ of Shandong province.

\section{Opportunities}

\subsection{Promotion of Huge Potential Benefits}

The new economy is the global economy taking knowledge as the main form of capital and information technology, biotechnology and other emerging technology as driving force for growth. Electronic commerce is the outcome of IT technology involving in economic field and network economical development, and is the main means of exchange and important component of the new economy.

Erin data shows that $67 \%$ of the enterprises admit their partners increase and business channels are wider after the application of electronic business and $58 \%$ of the enterprises admit their customers and sales increase. In the global crisis, the situation of small and medium-sized enterprises using electronic commercial platform for network trade is far superior to enterprises of traditional off-line mode. The rate that offline enterprises mess up is as high as $8412 \%$, and the rate of online enterprises is only $1618 \%$. Besides, in the business confidence index, $65 \%$ of online small and medium-sized enterprises have confidence and ability to pull through economic difficulties. But less than $10 \%$ of offline enterprises have confidence.

For enterprises in trouble, it's necessary to reduce operation cost and expand demand. And e-commerce has become one of the best means. Electronic business make the traditional business process electronic, digital reduce redundant Labour and the investment of manpower and material resources. Due to characteristics of open and global, though the constraint of existing channels and market bottleneck, electronic commerce provided important way for enterprises to open new markets and seek business opportunities.

At the same time, the electronic commerce makes the traditional business activities become more convenient and efficient. Electronic commerce relates suppliers, vendors, producers and customers together with the maximization network, improving the efficiency of the supply chain collaboration and greatly enhancing the ability of the enterprise responding market.

\subsection{The Development Environment}

GNP of Henan is more than $\$ 3500$. Henan has entered the development stage of industrialization and urbanization. At present, the construction of the central economic rises to be a national strategy, which provides a rare opportunity for development in Henan. E-commerce has many advantages like low transaction cost, high efficiency and big market. Many enterprises actively develop electronic business market. In addition, the country intensifies the funds investment of related infrastructure construction. This accumulates experience and lays a certain material foundation for developing electronic commerce in our province. It also provides security of talents and technology and other aspects.

\subsection{The Function of Market Mechanism}

Henan is a big agricultural province, with rich tourism resources and human resources. It also forms a industrial system containing vehicle, machinery, electronics, chemical industry, metallurgy, building materials, food, textile, pharmaceutical and other categories. Development of electronic commerce can give full play to various advantages in our province. Constantly promote the application of electronic commerce in relevant industry. Build a development road of low cost, high quality, high benefit and improve the allocation of resources from the whole level.

\section{Threats}

\subsection{The International and Domestic Double Pressure}

On one hand, developed countries expand and penetrate to developing countries increasingly using technical and economical advantages. On the other hand, developed provinces and cities have formulated preferential policies and measures to attract high technical talents, increasing investment and promoting the development of informa- 
tion industry. Henan is facing international and domestic competition pressure. In recent years, along with the emphasis on information industry and the gradual improvement of industrial policy, increasing input of information industry makes information industry everywhere develop rapidly. Information products renewal speed is also more and more quickly. Consumers have more and more alternatives. There is increasing competition in information industry. Backed by advantages of personnel, funding and independent intellectual property rights and fast technology transformation and high market share, the information development speed was significantly higher in coastal areas than in the Midwest. Information development in Henan province is under pressure.

\subsection{E-commerce Laws and Regulations Are Imperfect.}

Electronic commerce trade, which is realized through computer and network, involves lots of legal problems. At present, China's e-commerce legislation and corresponding standard is still not good, and can't effectively guarantee the legal rights of the parties of the network trade.

\subsection{Coordination Problems of Different Department and Different Regions}

Electronic commerce is a vast and complex systematic project. Electronic commerce construction involves many departments, multiple industry and many areas. It requires a wide range of cooperation like information resources, electronic payment, safe authentication, trade circulation, tax and other levels. At present, a unified, harmonious, ordered electronic commerce system is still not yet built in China, which restricts the development of electronic commerce in Henan province to some extent.

At present, economic globalization and regional economic integration further develop. The trend of international industry shifts to developing countries and eastern industry to the central and western regions strengthens. The strategy that China promotes the rise of the central region is implemented at a high speed. Central industrialization, urbanization and agricultural modernization process taking Henan as the main body accelerate. It's the key period for Henan's rejuvenation. Henan has unprecedented challenges and opportunities. By means of SWOT analysis, we understand more about the strengths, weaknesses, opportunities and threats of electronic commerce development in Henan, which lays the foundation for formulating specific strategies adjusting to local conditions, and points out directions for electronic commerce development.

\section{References}

[1] Tian, H.W. and Zhu, S.F. (2008) Henan Information Industry Development Strategy Based on SWOT Analysis. Journal of Henan University of Science \& Technology: Social Science, 1, 76.

[2] Huang, J.S., Huang, S.L. and Lai, X.T. (2008) SWOT Analysis of E-Commerce Development in Jiangxi Province-One of the Studies of the Electronic Commerce Development Road in Jiangxi Province. Market Modernization, 5, 68.

[3] Tang, W.J., Xie, J.M. and He, J.F. (2010) China's E-Commerce Development Strategic Choice in Current Economic Situation. Science and Technology Management Research, 5, 36.

[4] China National Network Information Center (2009) Report on the Situation of China Internet Development.

[5] Yang, H.W. (2006) Report on the Situation of China Internet Development. Market Modernization, 10, 84.

[6] Shao, J.B. (2003) Brief Introduction of E-Commerce. High Education Press, Beijing.

[7] Zhao, H., Liu, W.W. and Li, W.S. (2010) Policy Environment Model Research of the Development of E-commerce in Liaoning Province. Journal Of Shengyang University of Technology, 5, 574.

[8] Seminar of Research and Development Center of the People's Government of Liaoning Province (2003) The Comparative Advantage and Tactics Adjusted and Transformed in Old Industrial Base of Liaoning. The Academy Periodical of the Cadre in the Government and the Party, 10, 26-28.

[9] Guidance of Construction of Central Economical Regions in Henan Made by the State Council. www.gov.cn

[10] The Construction Program for Central Economical Region (for Trial Implementation). http://www.huaxia.com/ytsc/hnsy/jczt/jdzyjja/08/2561044.html 


\section{Submit or recommend next manuscript to SCIRP and we will provide best service for you:}

Accepting pre-submission inquiries through Email, Facebook, Linkedin, Twitter, etc A wide selection of journals (inclusive of 9 subjects, more than 200 journals)

Providing a 24-hour high-quality service

User-friendly online submission system

Fair and swift peer-review system

Efficient typesetting and proofreading procedure

Display of the result of downloads and visits, as well as the number of cited articles

Maximum dissemination of your research work

Submit your manuscript at: http://papersubmission.scirp.org/ 